\title{
LOS PRIMEROS LIBROS IMPRESOS EN FILIPINAS (1593-1607)
}

\author{
POR \\ JORGE MOJARRO ${ }^{1}$ \\ University of Santo Tomas, Manila
}

\begin{abstract}
RESUMEN
El presente estudio repasa las principales aportaciones en el campo de la historia del libro en Filipinas, haciendo énfasis en los aportes de los primeros bibliógrafos y comentando los impresos xilográficos descubiertos en la segunda mitad del siglo XX. A la luz de las evidencias disponibles, se traza una cronología razonada de los primeros impresos - xilográficos y tipográficos- de Filipinas. Se arguye que el itinerario de títulos resultante es extraordinariamente indicativo de las estrategias y las prioridades de las órdenes misioneras, especialmente los dominicos, en el Sudeste Asiático.
\end{abstract}

PALABRAS CLAVE: Imprenta; Filipinas; chinos; lengua tagala; cristianización; Dominicos.

\section{THE FIRST BOOKS PRINTED IN THE PHILIPPINES (1593-1607)}

\begin{abstract}
This study reviews the main findings in the field of book history in the Philippines, focusing on the contributions of the first bibliographers and commenting on the xylographic imprints discovered in the second half of twentieth century. Based on available evidence, I present a reasonable chronology of the first books printed in the Philippines, both xylographically and typographically. I argue that the resulting list of titles is extraordinarily indicative of the strategies and the priorities of the religious orders, especially the Dominicans, in South East Asia.
\end{abstract}

KEY WORDS: printing press; Philippines; Chinese; Tagalog Language; Christianization; Dominicans.

Cómo CITAR ESTE ARTículo / CITATION: Mojarro, Jorge. 2020. «Los primeros libros impresos en Filipinas (1593-1607)». Hispania Sacra LXXII, 145:231-240. https://doi.org/10.3989/hs.2020.017

$\begin{array}{ll}\text { Recibido/Received } & \text { 07-02-2017 } \\ \text { Aceptado/Accepted } & \text { 25-06-2019 }\end{array}$

\section{Pardo de Tavera, Medina y Retana}

El estudio de la historia del libro en Filipinas atrajo el interés de varios eruditos que, entre 1893 y 1911, publicaron numerosos trabajos y bibliografías que son hoy de conocimiento obligado para todo filipinista, especialmente si se trata de conocer cualquier aspecto de la historia de Filipinas durante el período español. El itinerario de primeras publicaciones, sobre todo hasta el establecimiento definitivo de la imprenta dominica en la Universidad de Santo Tomás (1623), debe entenderse como un momento

1 jorge.mojarro@ust.edu.ph /

ORCID iD: https://orcid.org/0000-0002-1949-8289 fundacional y paradigmático dentro del desarrollo de la cultura en el archipiélago. En este sentido, el primer folleto de cierta consideración que aborda el tema de la imprenta en Filipinas, escrito por el ilustrado Trinidad Hermegildo Pardo de Tavera (1857-1925), no dudaba en afirmar, en el contexto del emergente nacionalismo finisecular, que «bajo la vigilancia de una censura siempre alerta, la prensa no ha sembrado más que ideas propias para mantener y extender en Filipinas el amor y la veneración a España, y la comunión de todas aquellas razas en la fe católica». ${ }^{2}$ Pardo de Tavera traza propiamente una historia de los impresores bastante incompleta, aunque con numerosos datos curiosos 
y atendiendo fundamentalmente a las obras impresas por dominicos, franciscanos y jesuitas. El investigador manileño ofrece alguna escueta noticia sobre las prensas de los agustinos y el arzobispado, y la obra muestra carencias cuando se adentra en las publicaciones del siglo XIX, que no parecen suscitar tanto interés en el autor. En cualquier caso, Pardo de Tavera no discute en profundidad el modo en que llegó la primera imprenta a Manila, dando por hecho que fue idea de los dominicos y que su impulsor fue Francisco Blancas de San José (1560-1614). Tampoco rastrea suficientemente en crónicas o manuscritos la mención de la llegada de la imprenta y concluye que la primera obra impresa en Manila fue Arte y Reglas de la Lengua Tagala, de $1610 .^{3}$ Desde la ventaja que nos otorga la perspectiva histórica, no podemos sino lamentar sus excesivas prevenciones al redactar el siguiente párrafo:

Un sabio orientalista holandés, el doctor J. Brandes, me escribió en 1885 desde Bali-Boeleleng (Indonesia), diciéndome que, ya en 1593, se imprimió en Manila una doctrina cristiana en español-tagalog con caracteres propios de esta última lengua. Otros orientalistas, cuando el último Congreso de Londres, en 1891, me dieron la misma noticia. Ninguno me dijo, sin embargo, dónde leyeron semejante cosa, ni mucho menos, que hubieran llegado a ver tal libro. ${ }^{4}$

Los descubrimientos bibliográficos del siglo XX vendrían a dar la razón, como se verá más adelante, a los orientalistas que el escepticismo de Pardo de Tavera ignoró, y su meritorio trabajo fue sobrepasado ampliamente durante los años sucesivos.

El verdadero impulso en el estudio de la imprenta filipina y el establecimiento de un catálogo de las primeras producciones impresas vino de la mano del trabajo de dos eruditos bibliógrafos, el español Wenceslao E. Retana (1862-1924) y el chileno José Toribio Medina (1852-1930), cuyos desacuerdos académicos y mutuas críticas a lo largo de veinte prolíficos años no estuvieron reñidos con la caballerosidad y el común deseo de contribuir al conocimiento de la historia del libro en Filipinas. La calidad de sus estudios y la importancia de sus aportaciones los convierte, con toda justicia, en los fundadores de los estudios bibliográficos del archipiélago y en referencia obligada en la historia del libro en Filipinas. ${ }^{5}$

El primer borrador de los estudios bibliográficos de Retana apareció ya en $1893 .{ }^{6}$ Tras este breve ensayo, vio la luz en Santiago de Chile el primer trabajo de enjundia acerca de los libros filipinos dentro de la serie de bibliografías hispánicas

Francisco Blancas de San José, OP. 1610. Arte y Reglas de la Lengua Tagala, Bataan: Thomas Pinpin. Se conoce la existencia de cuatro ejemplares de esta obra; de la copia de la Biblioteca Nacional de España (Madrid) se hizo edición facsimilar (Madrid: AECI, 1997) con estudio introductorio de Antonio Quilis.

4 Pardo de Tavera 1893, 8-9.

5 En lo que se refiere a los primeros estudios bibliográficos, se ofrecen algunos datos adicionales en la espléndida tesis doctoral de Hill 2015, 15-19.

6 "Apéndice "B", en Martínez de Zúñiga 1893, 93-352. En este mismo apéndice se incluye la primera bibliografía elaborada por Retana, que será ampliada en sucesivos trabajos suyos hasta culminar en el monumental Aparato Bibliográfico de la Historia General de Filipinas (Retana, 1906). Hemos estudiado las disputas en cuestiones bibliográficas que Retana mantuvo con estudiosos contemporáneos y el proceso de gestación de su obra mayor en Mojarro en prensa. coloniales que venía publicando con asiduidad el erudito chileno José Toribio Medina. ${ }^{7}$ Este estudio sería completado por otros dos catálogos publicados sucesivamente en 1897 y $1904^{8}$ donde no rectificó sus proposiciones iniciales ${ }^{9}$ a pesar de que fueron rebatidas convincentemente por Retana en sus contribuciones de 1899 y $1911 .{ }^{10}$ Con lo que, gracias estos preciosos trabajos, hacia 1911 ya habían salido a la luz los más importantes testimonios, se habían discutido varias teorías y Retana había conseguido establecer, pese a la ausencia de algunas pruebas definitivas, una cronología casi concluyente acerca de la intrincada historia de la fundación de la imprenta en Filipinas. ${ }^{11}$

\section{LA IMPRENTA XILOGRÁFICA}

Una primera distinción que cupo realizar tras la exhumación de algunos manuscritos del Archivo General de Indias (Sevilla) y el testimonio de los cronistas de las órdenes fue la existencia temprana de libros impresos según el sistema xilográfico chino, esto es, a partir del tallado de tablas de madera que después se hacían pasar tintados por el papel, frente a aquellos salidos de la imprenta tipográfica de tipos móviles, de origen europeo. A la llegada de los españoles a Manila existía una numerosa comunidad de comerciantes chinos de crucial importancia para la subsistencia de la colonia, dado que las autoridades chinas no habían permitido, como habían hecho con los portugueses en Macao, el establecimiento de españoles en su territorio y necesitaban, por ende, a estos comerciantes para realizar las transacciones. ${ }^{12}$ La misma evangelización de esta comunidad china, los denominados 'sangleyes', se impuso como un objetivo prioritario que podría facilitar, más tarde, la introducción de los misioneros en China. ${ }^{13}$

7 Medina 1896.

8 Medina 1897 y 1904.

Medina defendió por primera vez en un opúsculo de 1894 que la imprenta de los dominicos había sido traída desde Macao en 1590, dado que desde ese año no hubo más publicaciones en la colonia portuguesa. Retana adujo, sin embargo, que eso no era posible por tres razones: en primer lugar, los jesuitas jamás habrían transferido una imprenta a los dominicos en aquellos tiempos debido a las malas relaciones entre la Compañía y la Orden; en segundo lugar, la comparación de los tipos usados en los impresos de Macao y de Manila saca a relucir diferencias evidentes; por último, el dominico Francisco Blancas de San José, impulsor de la imprenta en Manila, llegó a Filipinas a mediados de 1595. Retana plantea que la imprenta de Macao fue llevada a Japón, probablemente por órdenes del visitador Alessandro Valignano (1539-1606), dado que en ese año se datan las primeras publicaciones niponas de los jesuitas. Véase al respecto Satow 1888.

10 Retana y Gamboa 1899 y, sobre todo, su fundamental Orígenes de la imprenta filipina. Investigaciones históricas, bibliográficas y tipográficas (Madrid, 1911), que tomaremos como referencia principal.

11 Durante este primer periodo de estudios, vieron la luz dos importantes bibliografías comentadas que añadieron nuevos títulos: Pardo de Tavera 1903 y Pérez y Güemes 1904. Una excelente visión de conjunto acerca de estos primeros estudios bibliográficos y los primeros libros impresos en Albalá 2008.

12 No debe olvidarse que para los misioneros, en un primer momento, Filipinas no fue más que una parada en su camino hacia la evangelización de territorios que se pensaban más prometedores. Cfr. Ollé 2002.

13 La bibliografía acerca de los sangleyes, comunidad de relevancia crucial en la vida comercial del archipiélago, es abundante. Cfr. GarcíaAbásolo González 2013 y Gil 2011. 
Ante la falta de imprenta, los misioneros, deseosos de procurarse materiales con los que facilitar la propagación de la fe católica -labor que venían realizando desde que los primeros agustinos Ilegaron con Miguel López de Legazpi (¿1503?-1572) en 1565- dieron a la estampa en 1593 dos doctrinas cristianas, una en lengua tagala y española, y otra solo en lengua china, por el método xilográfico, como atestiguaba una carta escrita al rey desde Manila por el gobernador y capitán general Gómez Pérez Dasmariñas $(1539-1593)^{14}$ el 20 de junio de 1593:

Señor: en nombre de V. M. he dado licencia para que por esta vez, por la gran necesidad que había, se imprimiesen las doctrinas cristianas que con esta van, la una en lengua tagala, que es la natural y mejor de estas islas, y la otra en china, de que espero resultará gran fructo en la conversión y doctrina de los de la una nación y de la otra, y por ser en todo las tierras de las Indias más gruesas y costosas en las cosas, las he tasado en cuatro reales cada una, hasta que en todo V. M. se sirva de ordenar lo que se ha de hacer. ${ }^{15}$

El documento en cuestión da a entender que no se había impreso nada antes en las islas y pedía comprensión al rey por haberse adelantado a otorgar la licencia sin su consentimiento. Recordemos que una real cédula de 21 de septiembre de 1556, ratificada el 14 de agosto de 1560, prohibía la impresión de libros que trataran de las Indias sin especial licencia del Consejo Real de Indias; así pues, el gobernador y capitán general se disculpaba por haberse tomado la libertad de permitir las impresiones.

Otro curioso documento, titulado «Breve sumario y memorial de apuntamientos de lo que se ha escripto y se escribe de las Islas Philipinas fecho este año de 1593» viene a confirmar el mismo dato, aunque esta vez con el añadido de los precios: "Hanse impresso cartillas y cathecismos de la fee, uno en lengua española y tagala, que es la natural, y otra en lengua china, que se embian a Su Magestad: la tagala tassada en dos reales, y la china en quatro que se espera será de gran fructo». ${ }^{16}$

La existencia de la doctrina tagala se mencionaba en la obra Origine, formazione, meccanismo, ed armonia degl'idiomi (1785) del jesuita Lorenzo Hervás y Panduro (1735-1809), donde se copia el avemaría en tagalo, citando que «la salutación angélica en el tagalo de 1593, como se lee en la Doctrina Cristiana Tagalo-Española, que con caracteres tagalos y romanos está impresa por los Padres Dominicos en su imprenta de Manila el año $1593 » .{ }^{17}$ No cabe duda de que

14 Gobernó Filipinas desde junio de 1590 hasta octubre de 1593, cuando fue asesinado a traición por las tropas chinas que lo acompañaban en barco hacia las Islas Molucas. Su hijo Luis le sucedió interinamente en el gobierno.

15 Medina 1896, XIX. El documento había sido ya dado a conocer por Retana, sin que Medina lo supiera, en las páginas de La Política de España en Filipinas, n. 97 (23 de octubre de 1894).

16 Tomo la cita de Gayo Aragón 1951, 11. Un extracto de este documento, conservado en AGI (FILIPINAS, 6, R.7, N.109), fue dado a luz por Retana en octubre de 1894 en La Política de España en Filipinas, y en su totalidad en la edición de Morga 1909, 423-425. Los precios coinciden con los indicados en la doctrina en tagalo y en e Shih- $L u$, respectivamente, con lo que cabe la posibilidad que se esté refiriendo a estos dos impresos, aunque el Shih-Lu no sea una doctrina en sentido estricto.

17 Gayo 1951, 12. el erudito jesuita debió tener un ejemplar a la vista a la hora de redactar su obra. Las sagaces indagaciones de Retana, que nunca dudó de la existencia de las dos doctrinas aunque jamás las hubiera tenido a la vista, se confirmaron varios años después de forma consecutiva. La Doctrina Christiana en lengua española y tagala fue descubierta en 1946 y publicada en edición facsímil al siguiente año. ${ }^{18}$ La obra se imprimió anónimamente, aunque la portada indica que fue «corregida por los religiosos de las órdenes». Su autor fue probablemente el franciscano Juan de Plasencia quien, en carta fechada en Manila el 18 de junio de 1585 y dirigida a Felipe II, escribía:

En la lengua más general que hay en estas Islas tengo escrito algunas cosas, como es el Arte de la lengua y Declaración de toda la doctrina cristiana, y agora voy haciendo el Vocabulario. Son cosas muy necesarias para todos los ministros, si se imprimiese. Sería particular merced si V. M. nos haría hacernos merced mandallas imprimir en Mexico a costa de su Real Hacienda, y para esto enviar su cédula, que sería de grandísima utilidad para estas almas. ${ }^{19}$

En el Sínodo de Manila de 1582, ${ }^{20}$ convocado por el obispo Domingo de Salazar (1512-1594) para tratar los problemas más acuciantes de la nueva colonia y con representación de los miembros más preclaros de cada orden y de la sociedad civil de Manila, se mostró la citada doctrina tagala del padre Plasencia, que causó admiración entre los reunidos, y fue aprobada para que se hicieran copias y fuera usada por los misioneros. ${ }^{21}$ Lo más probable es que la obra se revisara y se corrigiera antes de su publicación, ya que Juan de Plasencia había fallecido dos años antes, en $1591 .^{22}$ No faltaron personas que le pudieron haber ayudado en la tarea:

No se puede hacer nada en el ministerio si los religiosos no aprenden la lengua de los naturales: en esto se an ocupado siempre los desta Prouincia, con gran cuidado, como tan desocupados de haciendas y negociaciones. Los Primeros padres Ministros dexaron muchos escritos en la lengua tagala y bicol: los mejores fueron los que dexaron los PP. Fr. Juan de Oliuer, Fr. Juan de Plasençia, Fr. Miguel de Talauera, Fr. Diego de la Asunción y Fr. Gerónimo Montes: hácese aquí mención destos Padres, por auer sido los primeros maestros de la lengua Tagala, y ser sus escritos tan comunes y tan bien reciuidos de todas las Religiones. No se an impreso, porque son grandes cuerpos, y no ay comodidad en este reyno para imprimir tanto. ${ }^{23}$

18 Doctrina Christiana 1947.

19 "Carta del P. Juan de Plasencia al Rey, en la que suplica se erija la Custodia de San Gregorio en Provincia...», en Pérez 1916, 288-289. El hecho de que pida la impresión de sus obras en México corrobora que no hubo imprenta en Manila hasta años después.

20 Acerca de este evento crucial en el devenir de las primeras décadas de presencia española en Filipinas, véase el estudio clásico de Porras Camúñez 1988.

21 La fuente es San Antonio 1741, 531. El cronista franciscano toma sus datos de la primera crónica franciscana inédita de Antonio de la Llave, contemporáneo de los hechos que se relatan. Retana (1911, 68) añade que "el hecho de que este catecismo estuviera aprobado desde 1581 induce a creer que fuese el favorecido en 1593».

22 Sánchez 2015.

23 Entrada de la seraphica Religion de nuestro P. S. Francisco en las Islas Philipinas (1649), ms. conservado en la Biblioteca Nacional de España (Madrid), recogido en Retana 1899, 49-50. Gómez Platero, en la ficha biográfica de Plasencia añade que «el año 1576 formó parte 
En cuanto al contenido de la doctrina, las dos primeras páginas están constituidas por un alfabeto y un silabario filipino prehispánico para el aprendizaje por parte de los frailes y de los nuevos tagalos cristianizados. ${ }^{24}$ Como peculiaridad, cada texto viene primeramente en español, después en tagalo romanizado, y a continuación en tagalo, lo que convierte a este impreso en un ejemplar de características únicas. El libro contiene el padrenuestro, el avemaría, el credo, la Salve Regina, los artículos de la fe, los mandamientos de la ley de Dios, los mandamientos de la Santa Madre Iglesia, los sacramentos, los pecados mortales, las obras de misericordia, la confesión y las preguntas; así pues, tal como ocurrió en los primeros libros impresos en México o en Perú, la doctrina incluía los conocimientos básicos que, en opinión de los misioneros, todo neófito de la religión católica debía conocer. ${ }^{25}$

Por su parte, la Doctrina Christiana en letra y lengua china fue descubierta en 1948 por José María González, historiador de los dominicos en China, en la Biblioteca Vaticana. ${ }^{26}$ La edición facsimilar, acompañada de un enjundioso estudio introductorio y una traducción al español, vio la luz tres años después, ${ }^{27}$ con lo que se confirmaba fehacientemente la existencia de las doctrinas citadas por el gobernador y capitán general Pérez Dasmariñas. Debió imprimirse al mismo tiempo que la doctrina en tagalo, o quizás un poco antes, a juzgar por la poca calidad de la impresión y considerando la prioridad que los dominicos otorgaron a la evangelización de la comunidad china. Su autoría se atribuye a dos pioneros de la sinología: la iniciativa y los primeros borradores del texto se deben a Miguel de Benavides (1552-1605), y Juan

de la primera misión desembarcando en Filipinas como los demás en el 77. Tuvo ya en España reputación de orador sabio y elocuente y en estas Islas añadió nuevos timbres a su merecida fama; apenas llegado a las Filipinas hizo conocimiento con un joven llamado Miguel, [...] y el Venerable Fr. Juan le enseñó la Gramática latina aprendiendo a la vez de él, como muy instruido que estaba en el idioma tagalog, esta lengua, en términos que a los dos años de permanecer en el país escribió los primeros Arte y Diccionario tagalog...» Entre las muchas obras que escribió, cita el biógrafo franciscano «un Catecismo tagalog de Doctrina cristiana el año 81 que el Sínodo celebrado aquel año en Manila aprobó». De entre los citados padres franciscanos cabe destacar a Juan de Oliver, a quien también se le atribuye una doctrina y que falleció en 1599; varios historiadores franciscanos le citan como el primero que llegó a dominar la lengua tagala y como autor de numerosas obras. Miguel de Talavera, por su parte, fue un fraile bilingüe ya que llegó de niño a Filipinas desde Nueva España con la armada de Legazpi. Entró en la Orden franciscana influenciado por el propio Juan de Plasencia y dejó algunos sermones impresos en tagalo antes de su fallecimiento en 1622. Véase Gómez Platero 1888, 17-18, 33-34 y 49-50. Así pues, cualquiera de estos hermanos de hábito habría podido colaborar en la redacción de la doctrina cristiana hispano-tagala.

24 Conklin 1991. Una defensa de la primacía de esta doctrina con respecto a la china y un análisis desde el punto de vista traductológico en Villoria Prieto y Villoria Prieto 1996.

25 Se comenta su contenido en Crossley 2016 y González 1985. Un primer e importante estudio filológico que compara el texto en baybayin con su correspondiente transcripción en tagalo latinizado en Guillermo et al, 2017, 1-59.

${ }^{26}$ Al parecer, el sinólogo francés Paul Pelliot mencionó su ubicación en el volumen 23 de la revista T'oung Pao (1924), pero la cita había pasado desapercibida para todos excepto para el historiador jesuita Henri Bernard en su Les Iles Philippines du Gran Archipel de la Chine (Tientsin 1936).

27 Doctrina Christiana. Primer libro impreso en Filipinas, ed. de J. Gayo Aragón y trad. de Antonio Domínguez. 1951.
Cobo (1546-1591), quien se incorporó a la vida del parián un año más tarde, debió corregir y hacer añadidos al texto, como parece deducirse de varias fuentes. Benavides llegó a Filipinas en la primera misión de dominicos en 1587, inició la predicación del evangelio entre los sangleyes ${ }^{28}$ y llegó a aprender la lengua china en muy poco tiempo. ${ }^{29}$ Así, el 13 de julio de 1589, el padre Cobo, que apenas llevaba un año en Filipinas, escribía: «el padre fray Miguel [de Benavides] los catequizaba y predicava en su lengua. Yo aún no sabía la lengua; pero el señor ha sido servido, que en poco tiempo se ha salido con algo". ${ }^{30} \mathrm{Y}$ más adelante, refiriéndose al mismo padre, afirmaba que: «...el P. fray Miguel los catequizaba y predicaba en su lengua, y hizo doctrina en su lengua. Yo aún no sabía la lengua...». ${ }^{31}$ El propio Juan Cobo no tardó en seguir los pasos de Benavides y convertirse en un docto sinólogo, como demuestran los trabajos de traducción que dejó inéditos antes de su repentina muerte. Es precisamente al frente del manuscrito de una de ellas, el Beng Sim Po Cam, una colección de sentencias de filosofía china, ${ }^{32}$ donde su compañero Miguel de Benavides nos notifica que:

Tradujo este libro el Padre Fray Juan Cobo, de la Orden del glorioso Padre Santo Domingo, varón muy docto, y en la vida verdaderamente apostólico, obispo que fue electo de una iglesia de las Filipinas: y yo, como único compañero y amigo suyo en la predicación de los Chinos, ofrezco en nombre suyo y en el de toda mi sagrada religión a V. A. este libro. La primera traducción de libro chino en otra lengua, y también la traducción primera de la doctrina cristiana en letras y lengua china este santo hábito la ha hecho. ${ }^{33}$

Así pues, mientras que Benavides atribuía justamente a Cobo la autoría de una traducción pionera, ocultaba con modestia su protagonismo en la traducción de la doctrina tras su «santo hábito» para honrar a los miembros de la orden dominica. ${ }^{34}$ El contenido de esta doctrina cristiana incluye,

28 La administración religiosa del parián de Manila había sido inicialmente adjudicada a los padres agustinos en 1581, pero fue transferida a los dominicos debido a la escasez de operarios y al poco fruto que habían obtenido. Sobre los malentendidos y los intereses cruzados de dominicos y chinos, véase el documentado artículo de Crewe 2015.

${ }^{29}$ La variante que hablaban era el min, de Fujian, de la costa sudeste de China. Sobre el padre Benavides, véase Mojarro 2016.

30 Se trata de su conocida "Carta sobre el parián de Manila», enviada a los hermanos de la provincia de Chiapas y Guatemala, e incluida en Remesal 1619, 580 y ss. Editada en Cervera Jiménez 2015, 84-101.

31 Ibíd., 582. La expresión "hacer doctrina» la entendemos en el sentido de escribir un librito básico de rezos y reglas, puesto que nos parece redundante que signifique «catequizar», algo que afirma palabras antes.

32 Se ha reeditado en numerosas ocasiones desde su primera edición impresa en 1924, pero la más acabada es Cobo 2005. de 1595 .

Sanz 1958, 195-196. La nota está fechada el 23 de diciembre

34 Suele mencionarse también en las discusiones en torno a la autoría de esta doctrina el siguiente fragmento extraído de la primera crónica dominica de Filipinas: «Este Padre [Juan Cobo] puso en lenguaje chino la Doctrina Christiana y los hizo que la aprendiesen y rezasen, así en la Iglesia en voz alta, como en sus casas particulares; cosa que hasta entonces no se había visto, y de que se les siguió grande aprovechamiento; y porque de la primera vez no pudo salir sin faltas, siendo en lengua tan diferente, y en tan breve tiempo aprendida, la volvió a reformar, y la puso con tanta perfección, que hubo después muy poco que reformar en ella por los ministros que después se siguieron» Cfr. Aduarte 1962, 219. Entendemos que debe ser una confusión debida a la fama de hombre culto que acompañó a Juan Cobo y su posible 
además de los típicos rezos, mandamientos y preguntas, una extensa sección dedicada explicar «el modo de rezar el Rosario con la descripción de cada uno de los quince misterios que componen esta devoción mariana, acompañando a cada uno su propia invocación». ${ }^{35}$ Esta explicación de los misterios del Rosario es un añadido propio típico de las publicaciones de la orden dominica. ${ }^{36}$ En cualquier caso, suponiendo que las dos doctrinas que Gómez Dasmariñas sean estas, no cabe duda de que la iniciativa de su impresión surgió de los miembros de esta orden. Llama poderosamente la atención que, habiendo sido impresas al mismo tiempo o con pocos meses de diferencia, la calidad de ambos impresos sea bien diferente. Cabe conjeturar que, mientras la impresión de la doctrina tagala fue realizada en el convento de Santo Domingo bajo la supervisión directa de los dominicos, la doctrina china fue llevada a cabo por un chino no convertido - los sangleyes pasaban a adoptar nombres españoles tan pronto como se hacían católicos- en el parián de Manila.

La aparición de estas dos doctrinas parecía haber resuelto la incógnita de los primeros libros impresos en Filipinas hasta que en 1952 el sacerdote católico Maurus Fang-Hao descubrió en la Biblioteca Nacional de España el Shih-Lu de Juan Cobo, impreso en marzo de $1593 .{ }^{37}$ El libro vino a complicar inesperadamente la cronología recién establecida por los bibliógrafos, ya que ningún documento anunciaba la existencia de esta original obra. El sinólogo holandés Piet Van der Loon defendió en un artículo muy erudito la posibilidad de que el Shih-Lu fuera en verdad la doctrina china "tassada en quatro reales» a la que se refería Dasmariñas. ${ }^{38}$ En el primer capítulo de la obra se dice que "este libro no ha sido compuesto por arbitrariedad sino bajo el mandato del Obispo y Gobernador de Manila», ${ }^{39}$ pero parece poco probable que el gobernador y capitán general Gómez Pérez Dasmariñas se refiriera al Shih-Lu simplemente como doctrina siendo en verdad un libro apologéticocientífico, a no ser que quisiera justificar más fácilmente la licencia otorgada. ${ }^{40}$ Van der Loon conjetura también, basado en las características físicas de la Doctrina china y en la variedad lingüística coloquial en la que se redactó, que esta debió ser impresa más tardíamente, durante la primera década del siglo XVII. ${ }^{41}$ Esta hipótesis es poco plausible, dado que para el año 1604 ya había imprenta en Manila,

implicación en las correcciones al texto primigenio, en las que también debió participar el dominico Domingo de Nieva (1563-1606). De ahí que se especifique en la portada "compuesta por los Padres Ministros de los Sangleyes, de la Orden de Sancto Domingo». Recordemos que Diego Aduarte (1566-1637) empezó a escribir la crónica veinte años después de los sucesos que narra y que se publicó por primera vez en 1640 .

35 Gayo Aragón 1951, 5.

36 Las misiones orientales dominicas forman hasta hoy la Provincia de Nuestra Señora del Rosario.

37 Cobo 1986. Una traducción más literal del título sería «Tratado de la Doctrina de la Santa Iglesia y ciencias naturales», que, además, hace más justicia a su contenido. Cfr. Sanz 1958, 239. Algunas puntualizaciones a esta edición en Chan 1989.

38 Van der Loon 1966. Esta hipótesis es seguida por Quirino 1973, Jose 1992, Totanes 2008 y Donoso 2010.

39 Cobo 1986, 100.

40 Véase la nota 15.

41 También afirma que la doctrina y los misterios del Rosario, aunque se publicaran en el mismo volumen, fueron redactadas independientemente por dos personas diferentes. Cfr. Van der Loon 1966, 14. con lo que al menos la portada y los preliminares hubieran debido imprimirse con los nuevos tipos móviles, como se hizo con los libros de Domingo de Nieva y Tomás Mayor. ${ }^{42}$ Por otro lado, no nos debe sorprender que la variedad lingüística de lengua china preferida para la traducción de la doctrina fuera la más popular, puesto que el público para el que se había redactado la obra eran mercaderes, navegantes y pescadores del parián a los que se quería evangelizar con conceptos básicos y de fácil comprensión, y que difícilmente podrían estar interesados en la lectura de un texto publicado en chino clásico. Tampoco se entiende que un libro tan pobremente impreso sea posterior a libros tipográficamente más cuidados. ${ }^{43}$ Parece improbable que se imprimiera un libro tan complejo como el Shih-Lu antes que la Doctrina, de contenido más básico y de la que había tanta necesidad. Que la impresión la llevara a cabo un chino no cristiano, Keng Yong, de hecho indicaría la prontitud con que se llevó a cabo, cuando aún no había suficientes conversos en esa comunidad. Por último, la inconsistencia de los caracteres que arguye el propio Van der Loon podría indicar que para entonces los padres dominicos aún no dominaban suficientemente bien la lengua. A falta de nuevas referencias que nos orienten, no nos es posible llegar a una conclusión definitiva, aunque planteamos la fecha de 1592 o principios de 1593 como fecha tentativa de impresión de la Doctrina china ${ }^{44}$ ya que, para entonces, los dos autores que con toda probabilidad compusieron la obra ya habían salido de Manila para realizar diferentes misiones ${ }^{45}$ y habrían dejado la obra lista para ser impresa. ${ }^{46}$ Un factor histórico que ha sido pasado por alto es que inicialmente los dominicos concentraron gran parte de sus esfuerzos misioneros en esta comunidad de chinos de Manila porque confiaban en que el éxito evangelizador les allanaría la entrada en China. ${ }^{47}$ Esta estrategia explicaría que priorizaran la impresión de una doctrina cristiana en chino que facilitara su labor de apostolado.

42 Gayo 1951, 2.

43 Una idea bastante peregrina es la que defiende Medina 1990. Esto es, que el Shih-Lu y la Doctrina china se publicaron conjuntamente. La propuesta debe descartarse inmediatamente: el tamaño de los signos y las páginas es totalmente diferente, y mientras que el primero se imprimió por ambas caras de la página, la segunda solo se imprimió por una.

44 Concordamos, pues, en esta cuestión, con Sanz 1958, 175-189.

45 Miguel de Benavides acompañó al obispo Domingo de Salazar a la Corte de Madrid en junio de 1591, tras intentar frustradamente establecer una misión en China. Juan Cobo fue designado por el gobernador para intermediar con el shogún Hideyoshi, que amenazaba con invadir la isla de Luzón, y partió de Manila el 29 de junio de 1592 . El barco que lo traía de vuelta se hundió en las proximidades de Formosa a fines de ese mismo año. Cfr. Ocio y Neira 2000, 43.

46 Añadamos que el segundo parián de Manila - hubo varios - fue fundado en 1583 por el gobernador Diego Ronquillo y se encontraba justo entre el Convento de Santo Domingo y la Casa-Iglesia de San Gabriel, dentro de Intramuros. Duró, tras sufrir varias vicisitudes, hasta noviembre de 1593. Más tarde, se movió a Binondo, extramuros y al otro lado del río Pásig. Cfr. Ruiz Gutiérrez 2012.

47 No fueron los únicos: los franciscanos, con Pedro de Alfaro y Agustín de Tordesillas, tomaron la iniciativa, otra vez frustrada, de asentarse en territorio chino aún sin el permiso del gobernador de Manila, algo que causó revuelo en la ciudad y que molestó sobremanera a los jesuitas, que ya habían realizado algún pequeño avance de la mano de Michele Ruggieri (1543-1607) y temían que estas arriesgadas internadas estropearan lo conseguido hasta entonces. Véase Pérez 1916. 
Volviendo al sorprendente Shih-Lu, cabe reseñar que se trata de una obra inconclusa: «Por ahora temporalmente escribió algunos capítulos. Lo que queda del trabajo aún no está acabado. Casualmente recibió la comisión de ser legado de la nación ». ${ }^{48}$ Escrita en chino clásico y a modo de un diálogo irregular entre un padre y su discípulo, está dividido en nueve capítulos: los tres primeros tratan discusiones teológicas, mientras que el resto explica conceptos de cosmografía occidental, geografía e historia natural. Esto lo convierte en el primer libro que trata de introducir la ciencia europea en el mundo chino, ${ }^{49}$ adelantándose en algunos años a las obras de Matteo Ricci (1552-1610) e inaugurando la estrategia misionera de la adaptación cultural que siguieron los jesuitas años más tarde ${ }^{50}$ y que tanta polémica suscitó hasta mediados del siglo XVIII. La idea de publicar un libro de tales características le vino inspirada por el éxito conseguido por el catecismo en chino de Michele Ruggieri, publicado en 1584, bajo el título Tien-Chu Shi-Lu («Verdadera Exposición del señor del Cielo»), catecismo que el padre Juan Cobo leyó:

También el Padre de la Compañía que está en China ha escrito, y está impreso en letras chinas, un libro todo él de la unidad de Dios y de la creación del mundo y de los mandamientos explicados [...]. De éste no hablo de oídas, porque lo tengo yo, y estoy tan cierto de ello como quien lo ha pasado letra por letras; que así lo he pasado todo. Del cual me he aprovechado para las letras chinas, que después diré de ellas. Este libro está impreso en China año de mil quinientos y ochenta y cuatro. Anda públicamente en China, y de allí le hubimos nosotros. ${ }^{51}$

Sin embargo, hay diferencias radicales entre la obra de Ruggieri y la de Cobo, que la supera en amplitud de temas y en profundidad: mientras que la primera expone las verdades fundamentales de la religión y los deberes del cristiano a los no iniciados, la segunda reúne una serie de discusiones filosóficas y científicas para atraer al camino del Evangelio a la clase culta y letrada: por ello, la lengua elegida es el chino clásico, en contraposición a la lengua llana de la Doctrina. Tomando como modelo la Introducción al símbolo de la fe (1584) de fray Luis de Granada, ${ }^{52}$ obra con la que guarda evidentes paralelismos temáticos, trata de demostrar la existencia de Dios a través de la observación de la naturaleza; es la creación divina la que demuestra la sabiduría y perfección de Dios: Juan Cobo expone a través de numerosos ejemplos e incluso con algunas curiosas ilustraciones el comportamiento de plantas y animales, así como la cosmografía ptolemáica. Pero quizás lo más llamativo de este ensayo trunco es la adopción de una perspectiva y una conceptualización sínica en el discurso y en la argumentación. Ya se nos dice en el primer capítulo:

El Padre, si bien es un extranjero, humildemente escucha las buenas costumbres y tiene voluntad de instruirse en la Santa doctrina de China. Es más, día y

48 Cobo 1986, 378

49 Un análisis del contenido científico del libro en Cervera 2013.

50 La obra que inaugura esta nueva estrategia es la corrección del catecismo de Ruggieri por Matteo Ricci (1552-1610), publicada en 1604. Cfr. Fidel Villarroel: «Observaciones histórico-bibliográficas», en Juan Cobo 1986, 74.

51 Cobo 1986, 73.

52 Para una comparación de ambas obras, véase el trabajo de Borao Mateo 2012. noche piensa impacientemente en ella. Sabe que sólo con la doctrina se puede propagar la religión: sólo estudiando se puede saber; sólo intimando con los sabios y gentilhombres se puede dilatar la doctrina y propagar la religión. ${ }^{53}$

\section{E incluso se anima al intercambio de doctrinas:}

Para los chinos es natural venerar y creer la doctrina de China. Estudiarla es lo más natural. Para los extranjeros creer y seguir la cultura también es provechoso. Investigar esta doctrina no causa perturbación. Esta razón, esta doctrina, aunque la sigan los bárbaros del norte y del sur, los chinos, ¿̇no pueden seguirla? ${ }^{54}$

El Shih-Lu trata de hacer pasar la ciencia occidental y la teleología cristiana a través de una sinización conceptual: en ningún caso trata de acuñar palabras extranjeras en el chino - como sí ocurrió en el tagalo-, evita deliberadamente el uso de términos religiosos y busca la acomodación cultural a través de la terminología. La continua referencia a los clásicos del pensamiento chino - el Wu Ching y los cuatro libros de Confucio- busca el encuentro con el cristianismo partiendo desde la misma filosofía china. Como aclara el padre Villarroel, «echa mano de los libros sagrados de la tradición china para conducir al lector chino al Evangelio de Cristo». ${ }^{55}$

La obra escrita del padre Juan Cobo, llevada a cabo en brevísimo tiempo y con la ayuda de intérpretes, merece mayor atención de la que ha recibido hasta ahora especialmente por su pionera labor y su esfuerzo intelectual de intermediador cultural entre dos civilizaciones: si con el ShihLu inaugura la ciencia occidental en China, el Beng Sim Po Cam («Espejo rico del claro corazón»), manuscrito redactado entre julio de 1589 y junio de 1590, es la primera traducción a una lengua europea de un texto chino: una colección de sentencias y diálogos sapienciales de contenido moral extraídas de filósofos chinos y compilada por Fan Liben. ${ }^{56}$

\section{LA IMPRENTA TIPOGRÁFICA}

Haciendo salvedad de las varias atribuciones a tempranas obras impresas que carecen de consistencia, ${ }^{57}$ debemos sostener que, con toda seguridad $-y$ gracias a las indagaciones de Retana-, la primera imprenta en Filipinas fue creada ex nihilo por el cristiano chino Juan de Vera a instancias del dominico Francisco Blancas de San José:

Compúsoles muchos libros de devoción manuales, y porque no había imprenta en estas islas, ni quien la entendiese, ni fuese oficial de imprimir, dio traza cómo hacerla por medio de un chino buen cristiano que viendo que los libros del padre fray Francisco habían de hacer gran provecho, puso tanto cuidado en

53 Cobo 1986, 115.

54 Ibídem, 139.

55 Ibídem, 81.

56 Véase la nota 32

57 El bibliógrafo mexicano José Mariano Beristain de Souza atribuye al agustino Juan de Quiñones un Arte y Vocabulario de la lengua tagala, impreso en Manila en 1581, mientras que el jesuita Pedro Chirino adjudica "algunos tratadillos» al agustino Juan de Villanueva. Es significativo que los cronistas y biógrafos agustinos no hagan referencia alguna a la existencia de tales trabajos. Lo más probable es que se trate de obras que circularon manuscritas. Cfr. Gayo Aragón 1951, 16-17. 
este negocio, que vino a sacar, (ayudado de lo que le decían algunos que sabían algo) todo lo necesario para imprimir, e imprimió estos libros. ${ }^{58}$

El cronista dominico Diego Aduarte nos indica el nombre de la primera persona que fundió tipos en Filipinas en el capítulo referente a los trabajos llevados a cabo en el parián de Manila, aunque no nos informa del título de la primera obra impresa:

Juan de Vera [...] sólo atendiendo al mucho fruto, que se sacaría con libros santos y devotos, se puso al gran trabajo, que fue necesario para salir con imprenta en esta tierra, donde no había oficial ninguno, que le pudiese encaminar, ni dar razón del modo de imprimir en Europa, que es diferentísimo del que ellos tienen en su Reino de China [...]; vino a salir con lo que deseaba, y fue el primer impresor que en estas tierras hubo... ${ }^{59}$

Dado que el padre Blancas, promotor de la imprenta tipográfica, no se asentó en Binondo, lugar de residencia del chino Juan de Vera, hasta abril de 1602 , no cabe pensar que se imprimiera libro alguno mediante esta técnica con anterioridad a esta fecha. Es precisamente 1602 la fecha en que sitúa el historiador dominicano Alonso Fernández la impresión del Libro de las Excelencias Nuestra Señora del Rosario, del cual afirma "que fue el primero que de esta materia ni de otra materia allá se ha impreso». ${ }^{60}$ El propio Fernández vuelve a citar la obra en su Historia de los insignes milagros... (1613), junto a otros títulos, pero citando de todos pie de imprenta en Bataán, donde Blancas misionó hasta abril de $1602,{ }^{61}$ lo cual debe ser una confusión, pues sabemos que sus obras hasta 1607 se imprimieron en Binondo. Las informaciones de Aduarte y Fernández no tienen por qué ser contradictorias: lo más probable es que el Libro de las Excelencias de Nuestra Señora del Rosario en efecto existiera, se imprimiera en Binondo durante la segunda mitad de 1602 y que lógicamente lo hiciera por el sistema xilográfico. ${ }^{62}$

El más antiguo impreso tipográfico filipino que se conoce de visu es Ordinationes Generales (1604), un volumen en octavo de tan solo ocho páginas que contiene las ordenanzas de conducta para los miembros de la Provincia del Santo Rosario. Las ordenanzas fueron redactadas en México en diciembre de 1586 por Juan de Castro (1527-1592), quien formó parte de la expedición fundacional que llegó a Cavite en julio de $1587 . .^{63}$ Este pequeño volumen, del que no debieron imprimirse demasiados ejemplares puesto que estaban destinados a repartirse entre los miembros de la corporación dominicana, compite en antigüedad con otro publicado el mis-

58 Aduarte 1962, II: 28.

59 Ibídem, I: 176.

60 Fernández 1611, 303-304.

61 Las citas fueron extractadas por primera vez por Retana en su La Política de España en Filipinas (17 de julio de 1884).

62 Van der Loon 1966, 40-42. Cfr. nota 53. Gayo 1951, 596-601 fuerza la lectura del prólogo de Blancas de San José al Libro de las Quatro Postrimerías para concluir que el primer impreso tipográfico fue el Libro de las Excelencias del Rosario. Cfr. Donoso 2010, quien sigue a Gayo en esta cuestión.

63 El único ejemplar conocido se conserva en la Library of the Congress (Washington). Cfr. su edición facsímil: [Castro, J. de] 1954. Ordinationes Generales, incunable filipino de 1604. Editado por J. Gayo Aragón. Nosotros manejaremos la edición del mismo año de la revista UNITAS, véase Gayo 1954. mo año, pero del que tan solo conocemos una reimpresión de 1734 redescubierta apenas en 1951: Libro de las quatro postrimerías del hombre en lengua Tagala, y letra española, de Francisco Blancas de San José. ${ }^{64}$ En el prólogo de este Libro se encuentran unas palabras bastante clarificadoras:

Servirá Padres míos, esta obrilla si quiera de dar aviso a V. R. S. de cómo ya tenemos por la misericordia de nuestro señor impresión entera y perfecta en estas nuestras islas para más perfecto cumplimiento de nuestro ministerio: pues podemos enseñar a éstos nuestros hermanos, no sólo en voz predicando, sino también por escrito, escribiéndoles, ora en caracteres Españoles, para los que saben leer, ora en los propios suyos Tagalos, todo aquello que nos pareciera que ha de ayudar para que vaya muy adelante esta misericordia, que el Señor ha hecho con ellos, haciéndolos Cristianos. Otras obras mayores y más trabajadas tenía yo primeras que ésta, como un Confesionario copioso, Sermones, Reglas de las lenguas, pero el nuevo oficial no se atrevió a comenzar su oficio sino por ésta más pequeña. [...] Reciban pues V. R. S. Padres míos, Ministros del Evangelio de Jesucristo, esta obrita por muestra como digo de la nueva impresión. ${ }^{65}$

Caben aquí algunas puntualizaciones: en primer lugar, cuando Blancas afirma en la cita que tenía «otras obras mayores», se refiere a obras manuscritas de mayor importancia o tamaño que, en efecto, vieron la luz en los años sucesivos. En segundo lugar, debe tenerse en cuenta que la edición de 1734 del Libro de las quatro postrimerías tiene más de 230 páginas, lo cual constituye una obra de gran envergadura para un impresor que se iniciaba en el oficio. ${ }^{66}$ Gayo Aragón defiende en su estudio la anterioridad del Libro de las Excelencias del Rosario basando su aserto en el hecho de que se cite en el texto la existencia de tipos "suyos tagalos», es decir, moldes de letras del silabario filipino, y que estos debieron usarse para esa primera obra. ${ }^{67}$ Los tipos del tagalo existían y, quizás debido al tamaño de la obra, no se quisieron usar en el Libro de las quatro postrimerías, aunque sí se usaron en el Arte y reglas de la lengua tagala (1610). Además, Gayo Aragón trae a colación un detalle relevante: la portada del Libro de las quatro postrimerías indica que Blancas de San José era "predicador general», cargo que no llegó a poseer hasta el 14 de mayo de 1604. Y Ordinationes Generales debió imprimirse a últimos de junio del mismo año puesto que la licencia del provincial dominico Miguel de San Jacinto, está fechado el 24 de junio de 1604. En el caso de que el Libro de las quatro postrimerías se hubiera

64 Castillo y Kabangis. 1956. El ejemplar, único, se conserva en la Newberry Library de Chicago. Agradezco Matthew Hill que me diera a conocer el trabajo de Castillo y Kabangis, obra que comenta en su Intercolonial Currents, 32-33.

65 Transcripción modernizada extraída de las fotos de la edición de 1734 obtenidas en Newberry Library (Chicago).

66 Estimamos que una edición con tipos de letras más pequeños que aquella debería ocupar al menos unas 170 páginas. Dado el carácter propagandístico de la obra, es dable pensar que se imprimieron, al menos, unos trescientos ejemplares.

67 Gayo Aragón 1954, 596-601. El prólogo continúa con estas palabras: «Y ha sido así por cierto conveniente que no se ocupase ya mucho tiempo en cosas mías, por que se dé lugar a las mejores que V. R. S. deben de tener trabajadas». No cabe entender estas líneas sino como una modesta invitación a que sus hermanos frailes usen de la nueva imprenta para dar a luz las obras que debían tener manuscritas. 
impreso antes que las Ordinationes Generales, habría debido tardar menos de cuarenta días, que nos parecen insuficientes para que un oficial primerizo pudiera imprimir materialmente una obra de entre 170 y 230 páginas, a no ser que la portada fuera precisamente hecha en ese intervalo. ${ }^{68}$ Tampoco parece descabellado considerar que la primera obra que se mandara a imprimir en Filipinas fueran las brevísimas ordenanzas de los dominicos, si tenemos en cuenta que urgía su publicación; estas andaban manuscritas entre los frailes de Filipinas desde 1587 y se venían ratificando en cada uno de los capítulos provinciales que se venían celebrando en Manila. En cuanto a la expresión «comenzar su oficio por esta más pequeña», mi hipótesis es que Blancas de San José prefirió tomar en consideración el Libro de las quatro postrimerías dado que este era el primer libro de carácter evangelizador y de cierta entidad que se publicaba en el archipiélago, y que obvió el pequeño folleto de las ordenanzas, obra de su compañero de Orden. La indicación de Blancas de San José como «predicador general» y la ajustada cronología parecen otorgar a las modestas Ordinationes Generales el título de primer impreso tipográfico de Filipinas.

\section{CUADRO CRONOLÓGICO DE PRIMERAS OBRAS IMPRESAS EN FILIPINAS}

La lista cronológica de primeras obras impresas en Filipinas es, hasta que un afortunado hallazgo altere su orden, la siguiente:

\begin{tabular}{|l|l|l|}
\hline \multicolumn{1}{|c|}{ AÑo } & \multicolumn{1}{|c|}{$\begin{array}{c}\text { TítULO, LUGAR DE IMPRESIóN E } \\
\text { IMPRESOR }\end{array}$} & \multicolumn{1}{c|}{ AUTORES } \\
\hline $1592-1593$ & $\begin{array}{l}\text { Doctrina Christiana en letra y lengua } \\
\text { china, Parián de Manila: Keng Yong. }\end{array}$ & $\begin{array}{l}\text { Miguel de Benavides y Juan } \\
\text { Cobo }\end{array}$ \\
\hline 1593 & $\begin{array}{l}\text { Pien Cheng-Chiao Chen-Ch'uan } \\
\text { Shih-Lu, [Parián de Manila] }\end{array}$ & Juan Cobo \\
\hline 1593 & $\begin{array}{l}\text { Doctrina Christiana en lengua española y } \\
\text { tagala, Hospital de San Gabriel, Manila }\end{array}$ & Juan de Plasencia y otros \\
\hline 1602 & $\begin{array}{l}\text { Libro de las Excelencias del Rosario, } \\
\text { Binondo }{ }^{69}\end{array}$ & Francisco Blancas de San José \\
\hline 1604 & $\begin{array}{l}\text { Ordinationes Generales, Binondo: Juan } \\
\text { de Vera }\end{array}$ & Juan de Castro \\
\hline $1604-1605$ & $\begin{array}{l}\text { Libro de las quatro postrimerías del } \\
\text { hombre en lengua tagala, Binondo: } \\
\text { Juan de Vera }\end{array}$ & Francisco Blancas de San José \\
\hline 1605 & $\begin{array}{l}\text { Memorial de la vida christiana en lengua } \\
\text { tagala, Binondo: [Juan de Vera] }{ }^{70}\end{array}$ & Francisco Blancas de San José \\
\hline 1606 & $\begin{array}{l}\text { Memoria de la vida christiana en } \\
\text { lengua china, Binondo: Pedro de Vera }\end{array}$ & Domingo de Nieva \\
\hline 1607 & $\begin{array}{l}\text { Símbolo de la fe, en lengua y letra } \\
\text { china, Binondo: Pedro de Vera }{ }^{72}\end{array}$ & Tomás Mayor \\
\hline
\end{tabular}

68 Retana 1911, 70-71, propone la fecha de 1605, lo cual es perfectamente plausible.

${ }^{69}$ Título probable: no se conserva ningún ejemplar. Este sería el último de los cuatro impresos xilográficos.

70 No se conserva ningún ejemplar, pero se constata su existencia por reimpresiones posteriores. Cfr. Jose 1992.

71 Se conserva un ejemplar en la Österreichische Nationalbibliotek de Viena. Sus primeras páginas están impresas con la nueva imprenta, mientras que el resto, en chino, al modo xilográfico.

72 Copia completa en la Biblioteca de la Universidad de Erfurt (Alemania). Copias incompletas en la Biblioteca de la Universidad de Leiden (Holanda) y en la biblioteca del Archivum Romanum Societatis lesu (Italia). Se informa en las licencias que se vendía a ocho reales.

\section{SIGNIFICACIÓN DE LOS PRIMEROS LIBROS IMPRESOS EN} FILIPINAS

Hacia 1911 Retana había conseguido despejar la mayor parte de las incógnitas referentes a los libros impresos xilográficamente, la fundación de la imprenta en Filipinas y los primeros libros impresos a la manera europea. Así terminaban casi dos décadas de fructíferos estudios en las que Pardo de Tavera, Medina y los frailes agustinos Pérez y Güemes habían llevado a cabo importantes hallazgos. Un nuevo impulso, sin embargo, siguió a mediados del siglo XX con los sucesivos descubrimientos de la Doctrina Christiana en tagalo, de la Doctrina Christiana en lengua china - cuyas existencias se deducían de la carta de Dasmariñas-, y del Shih-Lu - libro del que no constaba referencia documental. Más de allá del prurito de saber cuál fue la primera obra impresa en Filipinas, lo que estos primeros estudios trataron de poner de manifiesto fue que la aparición de la imprenta en Manila, el itinerario de las obras que vieron la luz en el archipiélago durante el periodo colonial y la fundación de los primeros centros educativos fueron hitos de relevancia que dejarían una huella indeleble en la configuración sociocultural del archipiélago durante al menos tres siglos y medio.

A día de hoy son varias las incógnitas de carácter bibliográfico que quedan por resolver. La primera de ellas es la fecha exacta de publicación de la Doctrina Christiana en lengua china, obra que, en contra de la opinión de Van der Loon, no suponemos impresa en el siglo $\mathrm{XVII},{ }^{73}$ sino hacia 1593 o un poco antes. La segunda de ellas es el tipo de impresión con el que se llevó a cabo el Libro de las Excelencias del Rosario (1602), que tan solo conocemos por referencias, y que suponemos llevada a cabo por el método chino. La tercera cuestión que queda por dilucidar es el orden en que se imprimeron las Ordinationes Generales y el Libro de las Quatro Postrimerías, ambos de 1604 , en la que hemos defendido la posible anterioridad del folleto en latín.

En cualquier caso, el período 1593-1607 es extraordinariamente interesante desde el punto de vista bibliográfico porque el itinerario de publicaciones que nos ha llegado indica, por una parte, el inicial interés de los religiosos dominicos por la evangelización de la comunidad de sangleyes, evangelización que, eventualmente, pudiera servirles de puente para la entrada de los frailes de la Orden de Predicadores en China. La negativa de China a la entrada de frailes - los dominicos no se asentaron en Fujian hasta 1632- y la poca cosecha de conversiones entre los sangleyes fueron quizás los motivos por los cuales dejaron de hacer el esfuerzo de publicar libros en chino. Símbolo de la Fe (1607), de Tomás Mayor, libro extraordinario con claras semejanzas con el Shih-Lu, fue la última publicación en chino conocida. ${ }^{74}$ Una de sus censuras, firmada por fray Francisco de Herrera, es bastante explícita respecto a las grandes esperanzas que guardaban los frailes en este libro:

73 Vid. supra, notas 37 y 39.

74 Se le adjudica a Tomás Mayor la autoría de un Libro de las Excelencias del Rosario, impreso en Binondo en 1607, en el catálogo de Ocio y Neira, Misioneros Dominicos, 87. La fuente es el historiador dominico Juan López, quien no conocía de primera mano las misiones en Filipinas. Los misterios del Rosario están incluidos en el Memorial de Nieva. Bien pudiera ser que este sea el texto cuya autoría se le atribuye. 
Y así mediante el favor divino ha de ser de grandísimo fruto, al cual tomará Dios por medio para que se comience a predicar la fe en el Reino de China, en el cual aunque hay diversidad de lenguas según la variedad de las provincias, pero este libro, no sólo puede aprovechar en una $u$ otra provincia, sino en toda la China, por cuanto va escrito en caracteres chinos que corren en todo el reino. ${ }^{75}$

Es decir, Símbolo de la Fe, en lengua y letra china, impresa por Pedro de Vera en Binondo, constituye una prueba de cómo la penetración evangelizadora en China era, en última instancia, el objetivo misionero prioritario hacia el cual apuntaban los frailes dominicos. La obra de Tomás Mayor y el Shih-Lu, de Juan Cobo fueron impresos en Manila para que circularan en China entre la gente letrada del país. ${ }^{76}$ Por otra parte, las publicaciones en lengua tagala, en cuya comunidad de hablantes se producían más conversiones, irán ganando más importancia a partir de las producciones de Francisco Blancas de San José.

Para las órdenes religiosas, la imprenta fue una tecnología de vital importancia para el desarrollo de su trabajo. El hecho de que los dominicos fueran sus introductores y llevaran a cabo las primeras impresiones, que estuvieran a cargo -aunque no fueron los primeros- del parián de los sangleyes y que, hacia 1611, fundaran la Universidad de Santo Tomás, indica que poseían un innegable afán de liderazgo entre las órdenes religiosas que trabajaban en Manila.

La creación de la imprenta en Manila, que en el sudeste asiático contaba con los precedentes de Macao y Amakusa, supuso el nacimiento de una tradición intelectual y académica europea en el archipiélago y la implantación de una cultura que privilegiaba la palabra escrita desde los primeros años de la presencia española. Desde el primer momento las órdenes se decidieron, como en América, por la impresión de obras en lenguas autóctonas, y es muy probable que la doctrina en tagalo de 1593 contribuyera inadvertidamente a la estandarización del baybayin, el alfabeto prehispánico del archipiélago. En este sentido, y aunque se limitara al área de Manila, el impacto de la letra impresa $-\mathrm{y}$ de la escritura en papel- debió ser incalculable, pues por primera vez los indígenas, que vivían dentro de una cultura de transmisión oral, conocían un medio que perpetuaba las palabras en el tiempo, estandarizaba rezos y canciones, y actuaba como prueba en los acuerdos entre varias partes. En la producción de libros, además, participaba un gran número de profesionales que constituyen una prueba de la temprana presencia de un pequeño y activo grupo de personas letradas y con intereses intelectuales. ${ }^{77} \mathrm{El}$ arte de imprimir fue siempre llevado a cabo manualmente por gente de la tierra: chinos - Juan de Vera, Pedro de Vera, Luis Beltrán- o tagalos - Tomás Pimpín, Simón Pinpín, Jacinto Magarulau, Raymundo Magysa-. La original intención misionera de la imprenta, que reducía su producción a libros de tipo religioso (doctrinas, novenas, etc.) y a obras lingüísticas destinadas a los frailes, con el paso de los años se fue flexibilizando y evolucionó hacia la publicación de una tipología más amplia de textos de típica factura colonial:

\footnotetext{
75 Mayor 1607 sin paginar.

76 Chia 2011.

77 Hill 2015, 3.
}

relaciones de sucesos, historias misionales, crónicas de fiestas, memoriales, textos polémicos, etc., que rara vez permitió la publicación las obras de ficción.

Una vez establecida esta escueta y provisional lista de primeros libros filipinos, queda como tarea prioritaria realizar el estudio pormenorizado del contenido de estas primeras obras tipográficas; en especial de Libro de las quatro postrimerías, que contiene los primeros poemas -Blancas lo llama «coplas» - en tagalo, y de Símbolo de la Fe (1607), obra voluminosa en cuya escritura e ilustraciones se tienen evidencias de deudas textuales con la Doctrina china, el Shih-Lu y la Introducción al Símbolo de la Fe (1584) de fray Luis de Granada. Pero es este un trabajo que deben llevar a cabo - esperemos - expertos tagalistas y sinólogos. ${ }^{78}$

\section{FUENTES}

Aduarte, Diego de. 1962. Historia de la Provincia del Santo Rosario de Filipinas, Japón y China del Sagrado Orden de Predicadores. Primera parte. 2 vols. Editado por Manuel Ferrero. Madrid: CSIC.

Blancas de San José, F. 1997. Arte y Reglas de la Lengua Tagala. Editado por Antonio Quilis. Madrid: AECl.

[Castro, Juan de.] 1954. Ordinationes Generales, incunable filipino de 1604. Editado por J. Gayo Aragón, Manila: UST Press.

Cobo, Juan. 1986. Pien Cheng-Chiao Chen-Ch'uan Shih-Lu. Apología de la Verdadera Religión. Edición facsímil de Fidel Villarroel con traducciones al español y al inglés. Manila: UST Press.

Cobo, Juan. 2005. Espejo rico del claro corazón. Editado por Limei Liu. Madrid: Letrúmero.

Doctrina Christiana. The first book printed in the Philippines. 1947. Editado por Edwin Wolf, 2nd. Washington: Library of the Congress.

Doctrina Christiana. Primer libro impreso en Filipinas. 1952. Edición de Jesús Gayo Aragón y trad. de A. Domínguez. Manila: Universidad de Santo Tomás.

«Entrada de la seraphica Religion de nuestro P. S. Francisco en las Islas Philipinas (1649)». 1895. En Archivo del Bibliófilo Filipino, W. E. Retana vol. 1, 49-50. Madrid: Imprenta de la Viuda de M. Minuesa de los Ríos,.

Mayor, T. 1607. Simbolo de la Fe, en lengua y letra china. Binondoc: en casa de Pedro de Vera, china cristiano.

Remesal, Antonio de. 1619. Historia de la Provincia de S. Vicente de Chyapa y Guatemala e la Orden de Ntro. Glorioso Padre Sancto Domingo. Madrid: Francisco de Angulo.

San Antonio, Juan Francisco de. 1741. Chronicas de la Apostolica Provincia de San Gregorio de Religiosos Descalzos de N. S. P. S. Francisco en las Islas Philipinas, China, Japón, \& c... vol. 2. Sampaloc: Convento de Nuestra Señora de Loreto.

\section{BibliografíA}

Albalá, Paloma. 2008. «Imprenta en Filipinas». En Diccionario histórico, geográfico y cultural de Filipinas y el Pacífico, coord. Leoncio Fernández Cabrero, Miguel Luque Talaván y Fernando Palanco Aguado, tomo 2, 457-467. Madrid: AECID - Fundación Carolina.

Borao Mateo, José Eugenio. 2012. «Observaciones sobre traductores y traducciones en la frontera cultural del Mar de China (siglos XVI y XVII)». En Historia cultural de la lengua española en Filipinas: ayer y hoy, ed. Isaac Donoso, 23-52. Madrid: Verbum.

Castillo y Kabangis, José del. 1956. El impreso tipográfico príncipe filipino. Manila: Oficina de Bibliotecas Públicas.

Cervera Jiménez, José Antonio. 2013. Tras el sueño de China. Agustinos y dominicos en Asia Oriental a finales del siglo XVI. Madrid: Plaza y Valdés.

78 Para esta obra, véanse los análisis de Van der Loon 1966, 31-37 y Chan 2002, 229-230. 
Cervera Jiménez, José Antonio 2015. Cartas del Parián. Los chinos de Manila a finales del siglo XVI a través de los ojos de Juan Cobo y Domingo de Salazar. México D.F.: Palabra de Clío.

Chan, Albert. 1989. "A note on the Shih-Lu of Juan Cobo». Philippine Studies 37: 479-487.

Chia, Lucile. 2011. "Chinese Books and Printing in the Early Spanish Philippines». En Chinese circulations. Capital, commodities and networks in Southeast Asia. Editado por Eric Tagliacozzo y WenChin Chang. Durham-London: Duke University Press.

Conklin, Harold. 1991. «Doctrina Christiana, en lengua española y tagala. Manila, 1593». En Visions of a collector: the Lessing J. Rosenwald Collection in the Library, Lessing Rosenwald, 36-40. Washington: Library of Congress

Crewe, Ryan Dominic. 2015. «Pacific Purgatory: Spanish Dominicans, Chinese Sangleys, and the Entanglement of Mission and Commerce in Manila, 1580-1620». Journal of Early Modern History 19: 337 365. https://doi.org/10.1163/15700658-12342461

Crossley, John. 2016. "Doctrina Christiana. National treasure, world heritage». The Journal of History, LXII: 135-161.

Donoso, Isaac. 2010. «El humanismo en Filipinas». En Teoría del Humanismo, ed. P. Aullón de Haro, vol. VI, 283-328. Madrid: Verbum.

Fernández, Alonso. 1611. Historia Eclesiástica de nuestros tiempos.. Toledo: Viuda de Pedro Rodríguez.

Gayo Aragón, Jesús. 1951. «Ensayo Histórico-Bibliográfico». En Doctrina Christiana. Primer libro impreso en Filipinas. Manila: Universidad de Santo Tomás.

Gayo Aragón, Jesús. 1954. «Ordinationes Generales: Facsímile del ejemplar existente en la Biblioteca del Congreso, Washington, con un ensayo histórico-bibliográfico». Unitas 27 (3), 555-631.

García-Abásolo González, A. 2013. Murallas de piedra y cañones de seda: Chinos en el Imperio Español (siglos XVI-XVIII). Córdoba: Universidad de Córdoba.

Gil, Juan. 2011. Los chinos en Manila, siglos XVI y XVII. Lisboa: Centro Científico e Cultural de Macau.

Gómez Platero, Eusebio. 1888. Catálogo Biográfico de los Religiosos Franciscanos de la Provincia de San Gregorio Magno de Filipinas. Manila: Imprenta del Real Colegio de Santo Tomás.

González, A. 1985. «The sixteenth century Tagalog of the Doctrina Cristiana (1593): A first step in intellectualization ». Likha 8 (2): 1-36.

Guillermo, Ramón, Myfel Paluga, Maricor Soriano y Vernon Totanes. 2017. 3 Baybayin Studies. Quezon City: University of the Philippines Press.

Hill, Matthew. 2015. Intercolonial currents: printing press and book circulation in the Spanish Philippines, 1571-1821. Austin: University of Texas [tesis inédita].

Jose, Regalado Trota. 1992. Impresso. Philippine Imprints 1593-1811. Makati: Fundación Santiago - Ayala Foundation Inc.

Martínez de Zúñiga, J. 1893. Estadismo de las Islas Filipinas, o mis viajes por este país. Editado por Wenceslao E. Retana. Madrid: Imprenta de la Viuda de M. Minuesa de los Ríos.

Medina, José Toribio.1896. La imprenta en Manila desde sus orígenes hasta 1810. Santiago de Chile: el autor.

Medina, José Toribio. 1897. Bibliografía Española de las Islas Filipinas. (1523-1810). Santiago de Chile: Imprenta Cervantes.

Medina, José Toribio. 1904. La imprenta en Manila desde sus orígenes hasta 1810. Adiciones y ampliaciones. Santiago de Chile: el autor.

Medina, Miguel Ángel. 1990. «Paralelismo entre la "Doctrina Christiana en Lengua Española y Mexicana" y la "Doctrina en Lengua
China"». En Evangelización y teología en América, ed. Josep-Ignasi Saranyana, vol. II, 955-971. Pamplona: Universidad de Navarra.

Mojarro, Jorge. 2016. "Historia misional y literatura en un impreso de fray Miguel de Benavides, obispo de Nueva Segovia: Relación del estado de la fe (1601)». Philippiniana Sacra LI, 52: 277-294.

Mojarro, Jorge. En prensa. «W. E. Retana, the Aparato Bibliográfico, and the Birth of Philippine Studies», en Wenceslao E. Retana, Bibliographical Apparatus for the General History of the Philippines, ed. de Jorge Mojarro, vol. 1. Quezon City: Vibal Foundation.

Morga, Antonio de. 1909. Sucesos de la Islas Filipinas. Edición de W. Retana. Madrid: Librería General de Victoriano Suárez.

Ocio, Hilario y Eladio Neira. 2000. Misioneros Dominicos en el Extremo Oriente 1587-1835. Manila: Life Today Publications.

Ollé, Manuel. 2002. La empresa de China. De la Armada Invencible al Galeón de Manila. Barcelona: El Acantilado.

Pardo de Tavera, Trinidad Hermegildo. 1893. Noticias sobre la imprenta y el grabado en Filipinas. Madrid: Tipografía de los Hijos de M. G. Hernández.

Pardo de Tavera, Trinidad Hermegildo. 1903. Biblioteca Filipina. Washington: Government Printing Office.

Pérez, Ángel y Cecilio Güemes. 1904. Adiciones y continuación de "La imprenta en Manila» de Don José Toribio Medina. Manila: Imprenta de Santos y Bernal.

Pérez, Lorenzo. 1916. Origen de las Misiones Franciscanas en Extremo Oriente. Madrid: Imprenta de G. López del Horno.

Porras Camúñez, José Luis. 1988. Sínodo de Manila de 1582. Madrid: CSIC.

Quirino, Carlos. 1973. «The First Philippine Imprints». En Doctrina Christiana, The First Book Printed in the Philippines, iii-xi. Manila: National Historical Institute.

Retana y Gamboa, Wenceslao Emilio. 1899. La imprenta en Filipinas (1593-1810), con una demostración gráfica de la originalidad de la primitiva. Madrid: Imprenta de la Viuda de M. Minuesa de los Ríos.

Retana y Gamboa, Wenceslao Emilio. 1906. Aparato Bibliográfico de la Historia General de Filipinas. 3 vols. Madrid: Imprenta de la Sucesora de M. Minuesa de los Ríos.

Retana y Gamboa, Wenceslao Emilio. 1911. Orígenes de la imprenta filipina. Investigaciones históricas, bibliográficas y tipográficas. Madrid: Librería General de Victoriano Suárez.

Ruiz Gutiérrez, Ana. 2012. «El parián de Manila: origen y evolución de la alcaicería de los sangleyes». En Mirando a Clío. El arte español espejo de su historia, coord. María Dolores Barral, Enrique Fernández, Begoña Fernández y Juan Manuel Monterroso, 16151623. Santiago de Compostela: Universidade de Santiago de Compostela.

Sánchez, Cayetano. 2015. «Impresos Franciscanos Hispano-Filipinos 1593-1699 (Part I)». Philippiniana Sacra L, 51: 473-514.

Sanz, Carlos. 1958. Primitivas relaciones de España con Asia. Madrid: Librería General Victoriano Suárez.

Satow, Ernest. 1888. The Jesuit Mission Press in Japan. London: Edición privada.

Totanes, Vernon R. 2008. "What Was the First Book Printed in the Philippines?». Journal of Philippine Librarianship 28 (1): 21-31

Van der Loon, Piet. 1966. "The Manila Incunabula and the Early Hokkien Studies (I)». Asia Major XII: 1-43.

Villoria Prieto, Carlos y Javier Villoria Prieto. 1996. «Primer libro impreso en Filipinas: una traducción». Livius. Revista de Estudios de Traducción 8: 223-246. 